\title{
A STUDY BETWEEN TOTAL ABDOMINAL HYSTERECTOIMY AND NON-DESCENT VAGINAL KEY WORDS: HYSTERECTOIMY IN TERTIARY CARE CENTRE
}

\section{Dr Rekha Aseri * (OBG department dr snmc jodhpur)*Corresponding Author}

\section{Dr pankaj kumar} solanki

\section{(resident Doctor Microbiology Dr Snmc Jodhpur)}

Objective: To study the safe procedure, intra and postoperative complication between abdominal and non descent vaginal hysterectomy.

Materials and Methods: This prospective study was conducted in a period of six months in the Department of Obstetrics and Gynaecology mdm jodhpr. Out of 100 hysterectomies, 68 were Total abdominal hysterectomy and 32 were Non descent vaginal hysterectomy. Basic characteristics of study were, duration of surgery, blood loss during intraoperative, duration in hospital stay, intra and post operative complications were observed.

Result: Complication associate with Patients who had TAH was more than NDVH but there were no significant value in both groups.

Conclusion: NDVH is safe and better option ascompared to TAH with decreased cost effective, decrease blood lossduring surgery SO no need for blood transfusion, decrease complications during surgery and decrease post operative pain as compare to TAH and no scar.

\section{INTRODUCTION}

Hysterectomy is the common surgical procedure performed for non pregnant women.The common indication for hysterectomy are symptomatic leiomyoma, abnormal uterine bleeding,endometriosis, adenomyosis and uterine prolapse. The main approaches to performhysterectomy, abdominal, vaginal and laparoscopic or robotic surgeries. The vaginal approach to explore the uterus has gained popularity due to Vaginal route provide cosmetic benefit for comparison of the risks and benefits of hysterectomy shows that vaginal approach has potential health and economic benefits of reduced post-operative complicationsand pain. It provide shorter hospital stay which lower the economic burden on the patients. They return to faster, as the recovery timeis shorter than abdominal surgeries [.7];route of hysterectomy is mainly depend upon sizeand shape of uterus and vagina, accessibility to the uterus, extent of the extrauterine disease and the expertness of the surgeon.[3] The contraindications of non descent vaginal hysterectomy was narrow pubic arch, immobile uterus, previouscesarean section, enlarged uterus can be successfully attempted by non descent vaginal hysterectomy. [7]

The object of this study that in Total abdominal hysterectomy (TAH) and Non-descent vaginal hysterectomy (NDVH) procedure to assess the intra and post operative complications, hospital stay and blood loss during and after surgery in women with benign disorders.

\section{MATERIALS AND METHODS}

This prospective study was conducted in the Department of Obstetrics and Gynaecology,mdm hospital jodhpur. Total 100 patients requiring hysterectomy were selected randomly from the OPD in OBG department after detailed history of patient about age, parity, weight, her menstrual history and presenting complaints were noted. General, physical and pelvic examination was performed and proforma made... hose patients fulfilling the inclusion and exclusion criteria were include in this study. Out of 100patients, 68 had total abdominal hysterectomy while 32 patients had NDVH procedure.

\section{Inclusion Criteria}

1. Women having benign pathology.

2. Uterus $<16$ weeks size.

3. Mobile uterus.

\section{Exclusion Criteria}

- Uterine prolapse
- Pelvic malignancy

- Endometriosis / pelvic adhesion

Basic blood investigations were performed associate with ultrasonography to assess the size of fibroid and any adnexal finding in pre operativein patients.. All patients were also explained about the conversion from NDVH to TAH if needed any time of during surgery. In this study indication for surgery, duration of surgery, blood loss, and complications during and after surgery were analyzed.

\section{Statical Analysis}

The difference in mean was tested using independent sample student ' $t$ ' test and ANOVA test, the measures of association between the qualitative variables were assessed using chisquare test. The inference was considered statistically significant if the $p$ value was $<0.05$.

\section{RESULT}

Out of total of 100 hysterectomies, 68 patients underwent total abdominal hysterectomy while 32 cases underwent NDVH. The age group of those operated by abdominal routeranged between 45 to 60 years while the NDVH arm aged between 40 to 55 year.

The most common indication in both the patients were abnormal uterine bleeding, 54 in TAH versus 29 in NDVH group, followed by fibroid uterus ( 8 in TAH vs 1 in NDVH) while chronic pelvic pain (4), adenomyosis (1) and chronic cervicitis (l) were the other indications for surgery in TAH while adenomyosis ( 1 ) and chronic cervicitis (1) were the remaining indications for NDVH (Table

1). Table 1: Indications of surgerie

\begin{tabular}{|l|l|l|}
\hline Indications & TAH $(\mathrm{n}=68)$ & NDVH $(\mathrm{n}=32)$ \\
\hline AUB & $54(79.41 \%)$ & $29(90.62 \%)$ \\
\hline Fibroid & $8(11.76 \%)$ & $1(3.12 \%)$ \\
\hline Adenomyosis & $1(1.47 \%)$ & $1(3.12 \%)$ \\
\hline Chronic cervicitis & $1(1.47 \%)$ & $1(3.12 \%)$ \\
\hline Chronic Pelvic Pain & $4(5.88 \%)$ & $0(0 \%)$ \\
\hline
\end{tabular}

\section{Table 2:complications}

\begin{tabular}{|l|l|l|l|}
\hline Complications & TAH $(\mathrm{n}=68)$ & NDVH $(\mathrm{n}=32)$ & P value \\
\hline Over all & $24(35.29 \%)$ & $5(15.6 \%)$ & 0.12 \\
\hline UTI & $7(10.29 \%)$ & $3(9.3 \%)$ & 0.89 \\
\hline Paralytic ileus & $4(5.8 \%)$ & $0(0 \%)$ & 0.17 \\
\hline Febrile morbidity & $4(5.8 \%)$ & $1(3.1 \%)$ & 0.57 \\
\hline Respiratory tract & $3(4.41 \%)$ & $2(6.2 \%)$ & 0.70 \\
\hline
\end{tabular}




\begin{tabular}{|l|l|l|l|}
\hline Vault hematoma & $2(2.9 \%)$ & $0(0 \%)$ & 0.33 \\
\hline Bladder injury & $1(1.47 \%)$ & $0(0 \%)$ & 0.49 \\
\hline Bowel injury & $1(1.47 \%)$ & $0(0 \%)$ & 0.49 \\
\hline Blood transfusion & $2(2.9 \%)$ & $0(0 \%)$ & 0.33 \\
\hline Wound infection & $1(1.47 \%)$ & $0(0 \%)$ & 0.49 \\
\hline
\end{tabular}

We observed that overall complications withTAH was significantly more than NDVH,. Two patients developed vault hematoma need blood transfusion with TAH and zero with NDVH, but was statistically insignificant.

Other minor complications like UTI (7), paralytic ileus(4), febrile morbidity (4) and respiratory tract infections(3) were encountered more in the TAH group but not significant. one patients of TAH sustained bladder injury and one had bowel injury, but none detected while performing NDVH. UTI(3), RTI (2) and febrile morbidity(1) were the other minor complications seen with NDVH and no major complications were observed.

\section{DISCUSSION}

vaginal hysterectomies were indicated for prolapsed uterus or uterine inversion, but nowadays it can be easily performed for enlarged uterus due to fibroid or adenomyosis. The techniques like bisection myomectomy,wedge resection, slicing method, coring and use of Ligature vessel sealing system, used either individually or in combination has made the per vaginal removal of uterus feasible and safe. [1] The age of the subjects in between 45 to 60 years while the NDVH aged between 40 to 55 year.

,which is in line with the observation of Dr Suman Lata et al(2017).[5]

We observed that NDVH was less time consuming thanTAH where time taken to perform NDVH Rohidas P.Chavhan et al [7] and other studies [4] [,5 ] have shown similar results where NDVH was performed in significantly lesser time. This result depends upon the size of the uterus, any previous pelvic surgery leading to adhesion and the experience of the operating surgeon. [6]

Alike thefindings of Abrol S et al(2017), [5] while comparing theoverall complications between the two group, we foundthat TAH had more complications than NDVH.We did not observe any major complications like bowel or bladder injury in the NDVH group while these were in $\mathrm{TAH}$, but statistically insignificant. Vault hematoma was encountered in two cases of TAH which further required blood transfusion, In the present study, no intraoperative complicationsoccurred in the vaginal group and also no conversion ofvaginal route to abdominal approach occurred. On comparison of all the parameterswith other studies, our results were comparable to otherstudies. [1],[2],[4][5][6][7] NDVH was found to be safe and effective operative technique for benign gynaecological conditions and should be offered whenever possible, considering safety, better operative outcome and cost effectiveness.

\section{CONCLUSION}

NDVH is safe and practical procedure compared to TAH. The decrease in the blood loss reduces the needfor blood transfusion. The intraoperative complications andpost operative complications are relatively less with NDVH. In NDVH hospital stay reduces the economical burdenover the patients. Hence, in summary, NDVH issafe and effective procedure comparing with TAH.

\section{REFERENCES}

1. Balakrishnan D, Dibyajyoti G. A comparison between non-descentvaginal hysterectomy and total abdominal hysterectomy. J Clin DiagnRes. 2016; 10(1):11-4.

2. Rosy N, Roy BN,Naher L, Hayat S, Sultana N.Non-descent vaginalhysterectomy versus total abdominal hysterectomy-A case controlstudy. IOSR J Dent Med Sci.2017;16(12):24-7

2. Chavvan RP, Arora G, Pajai S. Comparative study between vaginaland

|www.worldwidejournals.com| abdominal hysterectomy in non-descent cases.Int J Sci Rep.2016;2(3):48-52. the route of hysterectomy for benign disease. Obstet Gynecol. 2017; 129 (6): 155-9.

4. Abrol S, Rashid S, Jabeen F, Kaul S. Comparative analysis of nondescent vaginal hysterectomyversus total abdominal hysterectomy inbenign uterine disorders. Int J Reprod, Contracept, Obstet Gynecol.2017;6(3):846-9.

5. Suman L, Pal A, Thakur R, Singh A. Comparison of abdominal, vaginaland non descent vaginal hysterectomy: Perioperative outcome. J MedSci Clin Res. 2017;5(9):27695-702

6. Gayathri KB, Sajana G, Manjusha P, Bhargav PRK. Non descentvaginal hysterectomy (NDVH) forbenign gynaecological disease: aninstitutional study on safety and feasibility from South India. IOSR JDent Med Sci (IOSRJDMS).2017;16(11):59-63.

7. Chavvan RP, Arora G, Pajai S. Comparative study between vaginaland abdominal hysterectomy in non-descent cases. Int J Sci Rep.2016;2(3):48-52. 